\title{
PREVENTIVE CONSERVATION FOR BUILT HERITAGE. ANALYSIS OF DIFFERENT MODELS AROUND EUROPE
}

\author{
DALIA STABRAUSKAITE \\ e-mail: dalstab@gmail.com, https://www.linkedin.com/in/dstabrauskaite/
}

Keywords: Preventive Conservation, Built Heritage Maintenance, Monumentenwacht

\begin{abstract}
This paper explores how preventive conservation for built heritage is promoted and implemented around Europe, compares the different practices, and identifies some of the necessary conditions for them to be effective and successful. It pulls together a broad range of initiatives including recently launched and lesser known schemes. Since Monumentenwacht was introduced in Netherlands, similar inspection service schemes have been launched in nine European countries. Comparative analysis shows a great diversity in their management, the spectrum of services, sources of income and other aspects. Other important models contributing to the improved maintenance of built environment include heritage centres, databases of contractors, one-off campaigns, conservation manuals, and maintenance enforcement. Interdependencies observed between them suggest that their co-existence is essential for preventive conservation system to be truly effective.
\end{abstract}

\section{INTRODUCTION}

Preventive conservation of built heritage is recognized as an essential part of sustainable heritage management. It can expand the life-span of buildings and their historic fabric, ensure the optimal use of financial, environmental resources and embodied energy, stimulate the market, contribute to the preservation of traditional craftsmanship, increase public safety and bring about many other benefits.

Variety of practices were identified that contribute to the improved maintenance of buildings in Europe. Based on the differences in objectives and methods applied, they were classified into three categories. Monumentenwacht type of practices take a hands-on approach and deal with actual historic buildings by providing services such as inspection, monitoring and minor repairs. Measures of education and information (heritage centres, one-off campaigns, databases, conservation manuals) are raising awareness and equipping heritage owners with knowledge of proper repair materials and techniques, qualified specialists in the area, and other relevant information. The third category (combination of support and enforcement) represents the view that maintenance of the built stock should be government and individual responsibility (not a choice) for which supporting legal acts and financial instruments need to be present.

Such spectrum was chosen not to simply list down the different existing initiatives but to get a clear overview of the current practices in the field of preventive conservation for built heritage, to analyse the different approaches and their sustainability. Research methods include a review of literature, desk-based research into projects and policies of different countries, face-to-face interviews and correspondence with heritage professionals, a survey of practical maintenance workshops' participants. This paper is a condensed version of the author's dissertation under the same title. 


\section{COMPARATIVE ANALYSIS OF MONUMENTENWACHT TYPE OF PROJECTS}

Monumentenwacht (hereinafter - MW) was set up in the Netherlands back in 1973 as an independent non-profit organisation. The aim was to prevent deterioration of cultural heritage with the means of annual inspection, temporary repairs and provision of professional advice. It started with one part-time team that operated in two provinces and gradually expanded to the whole country [1]. Now the organisation has over 100 employees that inspect more than 13000 buildings every year [2].

The success of this model inspired a number of other European organisations to implement it in other countries. Nine similar schemes were identified to have been applied since: Monumentenwacht Flanders in Belgium (since 1991), the Bath pilot scheme in England (2002-2003), Monumentendienst in Weser-Ems, Germany (since 2004), Műemlékőr in Hungary (2012-2014), the Traditional Buildings Health Check scheme in Scotland (since 2013) (hereinafter - TBHC), ProMonumenta in Slovakia (since 2014), the Maintenance Plan for the Romanesque Route in Portugal (2014-2018), HeritageCARE in Spain, Portugal and the South of France (since 2016), and FIXUS in Lithuania (since 2019). Some of them have been successfully running for years, others have just been launched, and there are those that seized to exist right after pilot projects were over (see Figure 1).
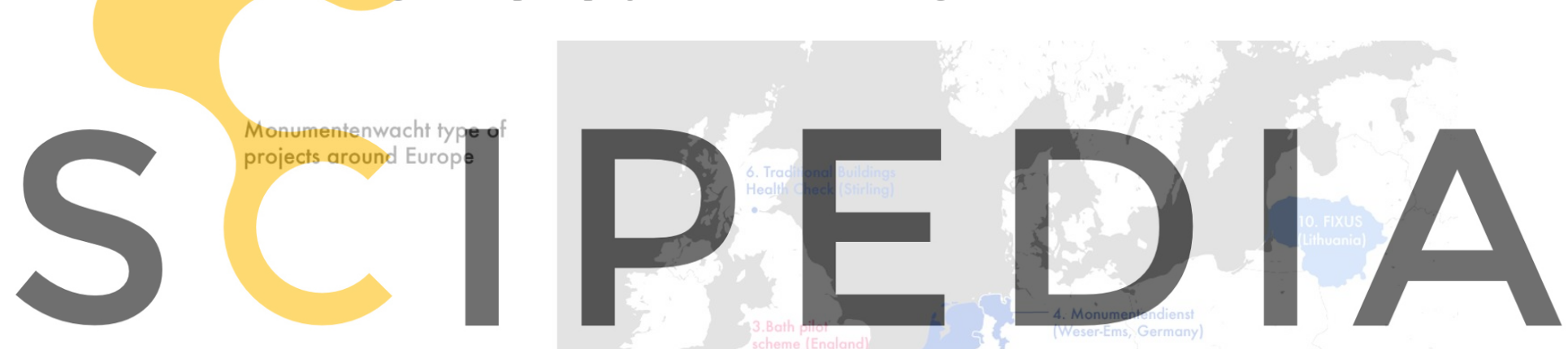

Register for free at https//www.scipedia.com to download the version without the watermark

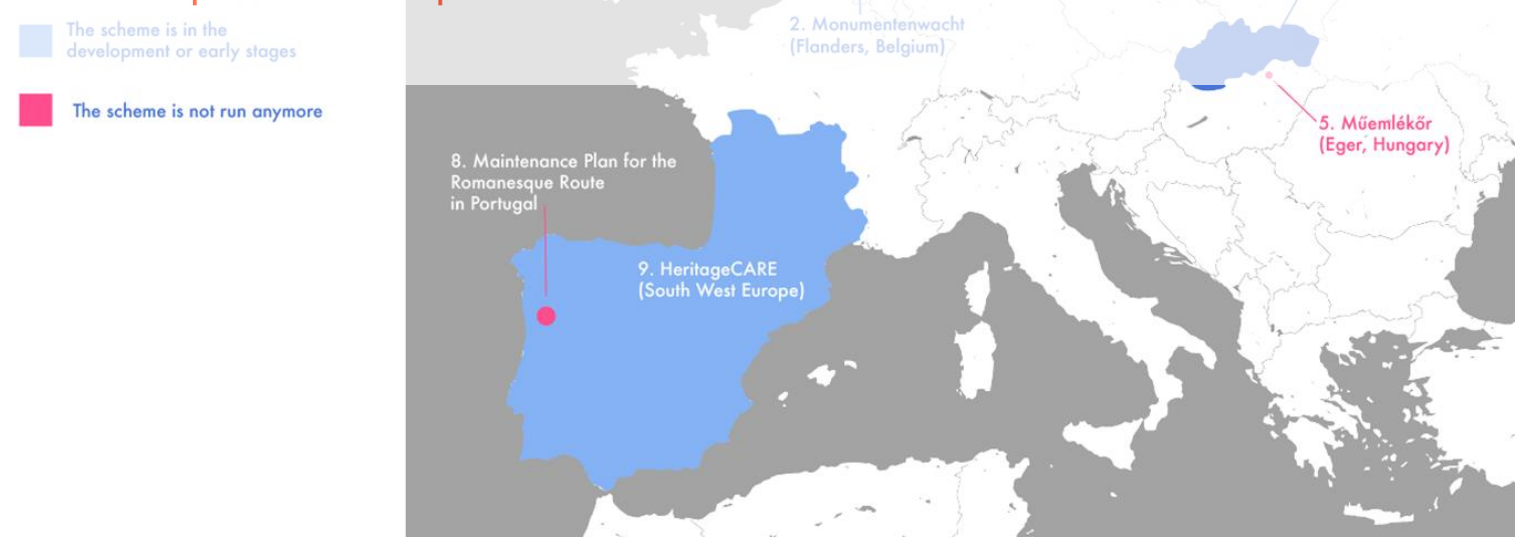

Figure 1: Schemes similar to Monumentenwacht Netherlands found around Europe. Prepared by the author.

Efforts were made to identify and present a full list of such projects in Europe. However, there were some deliberate exceptions made that should be noted. More than one such scheme has been found in Germany but only one was selected (Monumentendienst) as a more prominent example and also for the lack of accessible information about the other ones. Also, there have been attempts to establish similar schemes in Italy and Austria that fell through due to political reasons. 
The following subsections are aimed at highlighting these projects' differences and similarities, presenting common trends and challenges, rather than describing each of them individually.

\subsection{Services and objects of support}

The four main services provided by all 10 organisations analysed are visual inspection, minor but crucial repairs, the provision of maintenance advice, and the delivery of a condition report. Usually, the staff (or someone from the team) would also be able to answer owners' questions related to available funding, legal framework, appropriate energy efficiency measures and similar topics. In some places (e.g. Slovakia; Stirling), the owner cannot apply for a grant without being a member of the scheme and having a recent condition report.

Apart from these core services, some organisations also organise informational or training events; prepare maintenance related manuals; assist in preparing applications for funding; carry out inspections prior purchase or sale of properties; provide guidance during restoration or renovation works; provide tips on how to get comparable quotes from contractors, and provide other services.

Lithuanian project FIXUS stands out among other schemes in that it will carry out laboratory research of samples taken during inspections. Such a service is possible as scientific research of heritage objects is one of the main activities of the project promoter (Centre for Cultural Heritage). Findings (about salts, composition of plasters, types of mould and other) will inform cor

\section{In Flanders, a faitly}

Analysis report (or Lo

provided in the main

based on needed
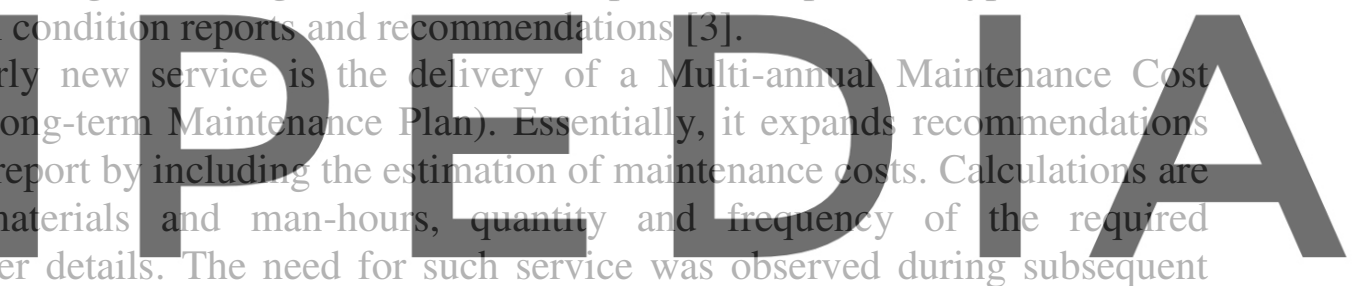

interventions and other details. The need for such service was observed during subsequent
inspections when some buildings were found in the same or worse condition than before. It

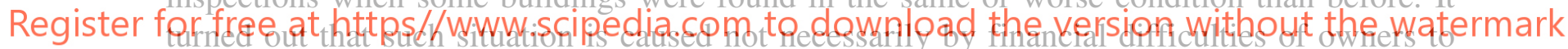

follow the recommendations but the lack of more specific instructions and cost estimates [4].

Survey carried out in Flanders showed that $92 \%$ of members are "strongiy interested in further support in maintenance of their valuable heritage, specifically for estimating the costs of the recommended works of preventive conservation" [5].

All of the organisations service historic buildings, however, some only work with listed (protected) properties under public or church ownership, while others (e.g. MW Flanders, Monumentendienst, TBHC, HeritageCARE) also include non-listed and privately owned objects. Non-listed historic buildings are not included in those schemes that are fully funded by public money. MW Flanders and some provinces in Netherlands are exceptional in that they provide services to other objects than buildings as well (movable heritage objects, interiors, maritime objects, in-situ archaeological heritage, historic gardens, cemeteries). They were gradually included as organisations grew in size and experience.

\subsection{Organisations and geographical scope}

There is a surprising diversity in the type of organisations that initiate and implement this model. In some countries, it is the governmental institutions of state level (in Slovakia, Lithuania) or municipal level (Hungary, Portugal) that take the initiative and assign their subordinate organisations to implement it. In other countries, the scheme is run by one or 
several independent non-profit organisations (though financially greatly dependent on public support). They highlight their impartiality as one of the most important traits of the service.

Some of the organisations were established specifically for the purpose (e.g. Monumentendienst Weser-Ems), others expanded their activities (e.g. Stirling City Heritage Trust). Some of the non-profits emerged bottom-up (e.g. MW Netherlands), others had guaranteed governmental support from the start (e.g. MW Flanders). However, the continuity of schemes is not assured by the initial support of governmental institutions. For example, the pilot project in the town of Eger, Hungary (Müemlékőr, en. Monument Guard) was coordinated by the research centre under the Ministry of Human Resources (The Gyula Forster National Centre for Cultural Heritage Management). Despite the success of the pilot, the project was discontinued when the Forster centre was closed due to the changes in political agenda and the reorganization of public administration.

The model has been found to be applied in areas that are very different in size - of a city, a region, a country and even several countries. Projects in cities (Bath, Stirling, Eger) were started as pilot schemes to test this model's feasibility on a small scale first. Schemes in small areas are easier to set up and manage quality wise but they are less economical and more vulnerable to changes in staff. Manager of TBHC explained that it is challenging to balance limited capacity ( 1 inspection team) with the right amount of marketing and the changing demand for services - periods when there are very few or too many bookings. Under the TBHC scheme, inspection of one building requires around half a day, and then another two days are needed for the preparation of a report (which is around 30 pages long). Thus, one team can only take organisations with less Schemes in larget systems to ensure the same Netherlands, an indeper up around 2 objects
than 5 to over 100 emp
areas have the benefit
same quality of servi
ndent drganisation exis

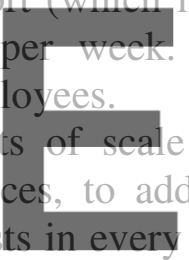
s around 30 pages long)
Among the researched
but require effective $m$
dress logistical and other
province - they work Thus, one
there are
managenent
issues. In
parately but all of them are affiliated members of an umbrella association. It advocates its members

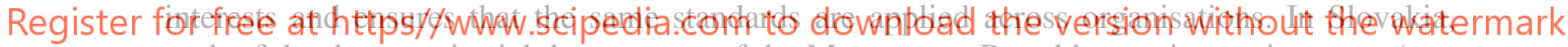
each of the three territorial departments of the Monuments Board has an inspection team (one team consists of 4 persons) to cover different regions.

The project of HeritageCARE is unique in that it covers three bordering countries (South of France, Spain, Portugal) with similar heritage, climatic conditions and common challenges. International and intersectoral collaboration of 19 organisations (universities and research centres, public institutions and private organisations) resulted in the development of progressive methods of inspection and reporting, comprehensive damage atlas and other tools.

\subsection{Sources of income}

A characteristic common to all the analysed schemes is dependency on public funding. As noted by Zoltán Erő (the managing director of architects' studio Palatium in Hungary), the market would be full of companies offering such maintenance services if it was a profitable business [6].

The three longest running of the analysed schemes (MW Netherlands, MW Flanders, Monumentendienst Weser-Ems) are supported by both local and state level governments with the biggest share coming from the former. It is worth mentioning that in all three countries decentralization policies are applied (especially Germany and Belgium that have federal governments; Netherlands is a decentralized unitary state). That may be one of the reasons why local authorities are more supportive of such schemes. 
Exceptional case, in terms of funding, is the Bath pilot scheme, which was grant-aided by three charities. However, the scheme only ran for 12 months and its continuation was considered not possible "without greater promotion and strategic engagement from the conservation authorities, better implementation of existing policy and financial \& fiscal stimulus" [7].

All the schemes launched after 2013 (except for TBHC) took advantage of EU/EEA funding. It was used for whether the preparation of the scheme (research) or for its first years of implementation (including acquisition of equipment). The grants were provided under the programmes of Interreg (for HeritageCARE, Muemlekor), EU Structural Funds (MPlan for Romanesque Route), and the EEA Grants (ProMonumenta, FIXUS projects).

The fact that public funding is essential for this model to work is widely discussed but often without the supporting numbers. To get a better understanding of the level of support that is needed, the income generated from the fees was compared with the overall annual budget. The following two membership-based schemes were taken as case studies:

1). The Traditional Buildings Health Check (TBHC) scheme in Stirling covers one small town. From its launch in October 2014 until the summer of 2019, it had attracted around 300 members. The annual budget needed to run the scheme is roughly $£ 170,000$. It should be noted that this is the budget of a "normal" year - all the set up costs (purchase of equipment and other) have been incurred in the previous years. Only around $£ 15,000$ of this amount is generated from membership fees and inspections, while the rest is the support from the Historic Environment Scotland (public body) [8]. Thus, only 8,8\% comes from the direct users of the service (herit

2). The MW schem operational for 44 year 2019 was 1,96 million constitute $35,5 \%$. Tha rest was Government $(8,7 \%)$ and a few other sources [9].
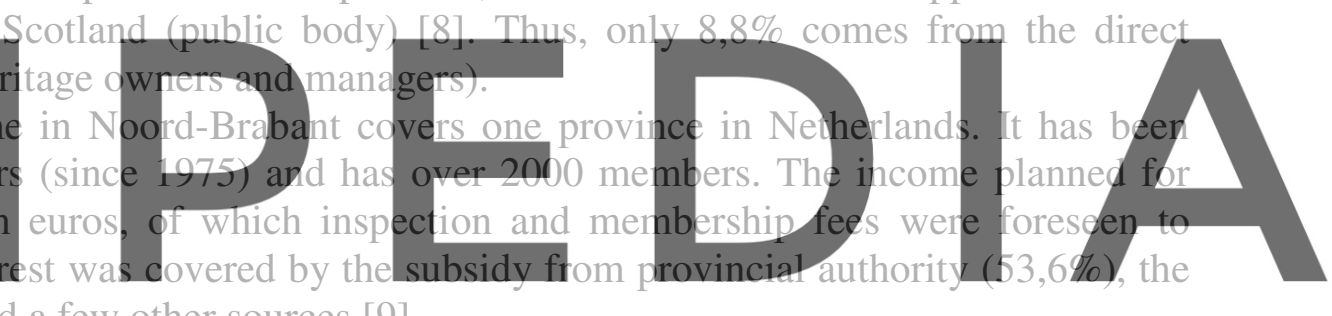

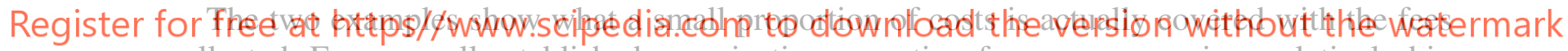
collected. Even a well-established organization operating for many years in a relatively big area generates only around a third of its income from members' contributions. The percentage is naturally even lower for a relatively new scheme operating in a small territory of one city.

\subsection{Pricing}

Majority of MW schemes are based on a membership system under which heritage owners pay an annual member fee and they are also charged for the services provided. However, there is a great variation in pricing policies.

The analysis of different schemes showed that the average annual membership fee is around 40 euros. Manager of TBHC shared that, despite the overall increasing interest in the scheme, $80 \%$ of members renew their membership for a second year, only $63 \%$ for the third, and $61 \%$ for the fourth. That is linked with the low demand (28\%) for annual re-inspections which are seen as too frequent [8]. As an incentive, in some provinces of Netherlands, reduced rate is applied when the membership is extended. In Flanders, operators with a large number of heritage objects can purchase a group membership. For example, every heritage owner of Riemst community in Limburg (there are 108 protected objects) can become a member of the scheme for free thanks to the municipal administration that obtained collective membership (for 1000 euros/year). The municipality also subsidizes inspection costs [5]. 
Fees for services are usually based on hourly rates. The lowest hourly rate amongst the analysed cases was 30 euros/hour (Monumentendienst, Germany). Every provincial organisation in Netherlands has a custom pricing policy. There, rates vary from 31 to 75 euros/hour which is influenced by the different size of support that comes from local authorities. Instead of an hourly rate, TBHC charges 150 to 195 pounds a day. Normally, organisations charge the owners additionally for the materials used on repairs. Some organisations also include travel expenses (whether a fixed "call rate" or based on a distance). In Flanders and Netherlands, services started to be provided to non-members as well but for higher (not subsidized) fees. For example, the usual hourly rate of MW Flanders services is 45 euros but for non-members it's almost twice the amount ( 80 euros).

There are big differences regarding the value-added tax (VAT) for repair services. In Scotland, the full rate applies, in Germany it's reduced (7\%), while in Netherlands such services are exempt from VAT.

In projects that are currently fully funded by the EEA Grants (FIXUS, ProMonumenta) no fees for heritage owners apply. Even after 2022 (the end of EEA supported period), the schemes are planned to be mostly supported by the Government and thus only very small charges are foreseen [10].

To sum up, the schemes that follow the model of MW Netherlands are similar in that they offer the same core services but they are definitely not pure 'copies' of the Dutch practice. There are significant differences in their management, sources of income, the size of geographical area cover

3 MEASURES OF

There are many different educational and information at improved maintenance of historic buildings. Four of them stood out to the author as the most common: heritage centres, one-off campaigns, databases of contractors, and

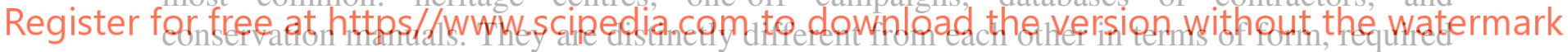
budget and staff, the impact that can be achieved, and other aspects. Each is briefly presented in the following sections.

\subsection{Heritage centres}

A heritage centre, in this context, refers to a non-profit organisation which provides consultations and/or trainings on heritage related topics to heritage owners, specialists and enthusiasts. Most of them are also carrying out activities of heritage research, documentation and dissemination, practical conservation, preparation of condition reports or similar. Such establishments are widespread in the Northern Europe, especially in Norway and Estonia. However, based on personal communication with heritage professionals from Scotland, Central and Western European countries, it seems that little is known about them outside Northern Europe.

Centres that actively provide services to heritage owners and the general public are indicated in the map (see Figure 2). Different colours are used only to signify more clearly to which country the centre belongs. This is not an exhaustive list but most of the important centres in Norway, the Baltics, Scotland and Iceland are believed to have been identified. Those that were considered as very low in activity or inactive were deliberately excluded. Situation in Sweden and Finland has not been investigated enough (due to time limitations 
and language barrier). Research done so far has not resulted in the discovery of any prominent centres but it is likely that some exist there as well.

Those centres that mostly focus on the training or the upskilling of craftsmen were also excluded as vocational education is another broad research topic. However, such centres address the issue of skilled workers shortage which directly affects the quality of repairs. In Norway, such training centres can often be found under cultural history and open-air museums (e.g. Buskerud, Midt-Troms, Ryfylke, Husasnotra and other museums).

\footnotetext{
Nordnorsk building preservation centre
}

The Røros Museum building preservation centre
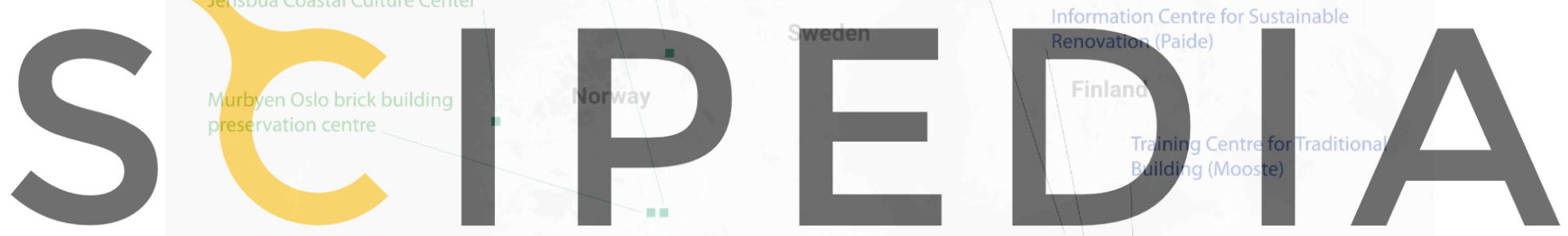

The Centre for Traditional Building Register for free at https//www.scipedia.com to download the version without the watermark

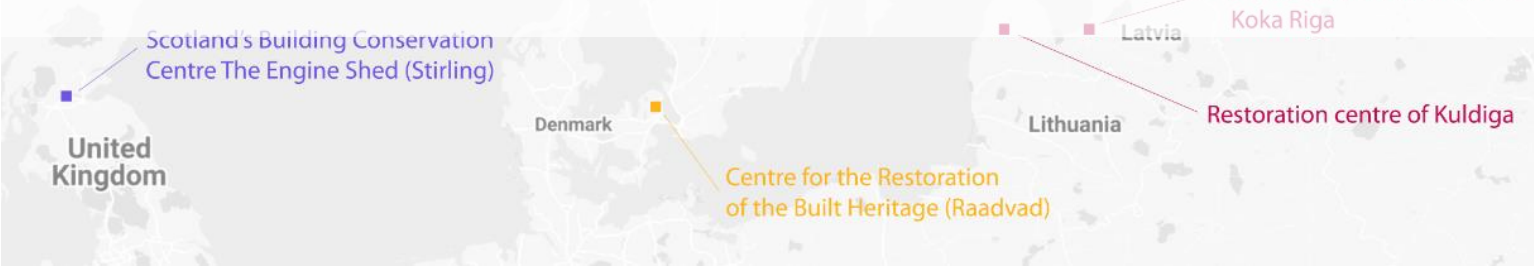

Figure 2: Locations of heritage centres. Prepared by the author.

One of the first centres to appear in the Baltic countries was the Information Centre for Sustainable Renovations (SRIK) established in 2001 in a wooden architecture neighbourhood of Kalamaja in Tallinn. It organizes trainings for heritage owners and specialists, provides consultations, delivers guidance publications and videos, organises various heritage related events. Importantly, in the same building a little shop "Majatohter" is established so heritage owners can easily get appropriate materials for maintenance and repair works. The centre has been supported by the Council (with gradually decreasing funding); it also generates some income from running the shop, from taking part in various international projects and other.

Many of the Nordic centres focus more on wooden architecture (as it is characteristic to the region) but there are exceptions. For example, the Murbyen Oslo centre specializes in historic 
brick buildings (that are built around 1850-1930). Its specialists can carry out a free initial inspection to assess the condition of building's facades and common areas. Recommendations on needed works, suitable materials, experienced craftsmen, possible sources of funding are provided in person and in a brief report/ inspection note. The Centre also organizes courses, seminars and city walks. It is financed by the Ministry of Climate and Environment.

The Building Preservation Centre in Reykjavik (operational since 2007) is only open for 2 hours per week. During that time heritage professionals provide free advice on the maintenance and repair of old buildings, there are also samples of suitable products for repairs, books and magazines on architectural conservation. It is the simplest of the analysed centres but a relevant example of how a heritage centre can be run even on a small budget.

\subsection{One-off campaigns}

There are many examples of one-off campaigns or short-term initiatives around the world for the improved maintenance of heritage. They often emerge as a response to the lack of public attention to a specific problem. Such initiatives can also help to test ideas and their feasibility before bigger investments are made. Normally, a small geographical area and/or a very specific topic is chosen to be tackled.

Events like this are generally considered beneficial but there is not much research measuring their real impact and effectiveness in the long-run (such as application of skills acquired after the workshop is finished). To understand the impact of such short-term

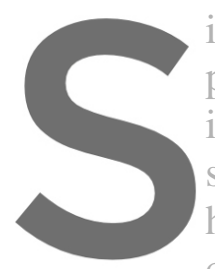
initiatives better, one specific case was chosen to be analysed
practical wooden windows conservation workshops for the pub
in 2016 . Each workshop lasted for 4 days so that participants
stage of the process. The size of the group per event was limite
hands-on approach. Workshops were led by experienced drat complemented with lectures and local excursions related to wooden heritage

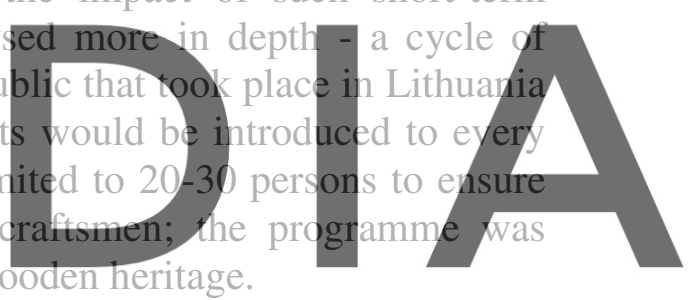

This specific case was chosen for the author had the experience of managing these

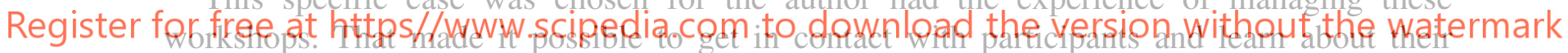

experience. An online survey was created and sent in July of 2019. That was perfect timing to collect the data as three years that passed after the workshops is a period long enough to apply such skills and knowledge in practice. 37 out of 70 participants to whom it was sent completed the survey (53\%).

More than half of the respondees (57\%) felt capable of applying the knowledge and skills gained to repair a window on their own, and $43 \%$ actually did apply them. $8 \%$ felt that they have applied the knowledge indirectly - in the process of contracting specialists for the repair works and knowing how they want them to be done. These series of events also worked as a platform for networking. A high proportion of respondents made relevant contacts with craftsmen $(43 \%)$ or used it as an opportunity to get a consultation from craftsmen on topics other than that of the workshop (41\%). Around a third made useful and interesting contacts with other participants $(32 \%)$.

In order to have a somewhat broader and longer lasting impact, an informational video was prepared in which every important stage of the process and recommendations by craftsmen were captured. That turned out to be a very effective measure. First, participants of the workshops found it to be a useful resource to refer to when carrying out the works on their own. Second, the video helped to reach a much broader audience - it has already been viewed over 7 thousand times [11]. Third, the leading craftsman said that a lot of people seeking for professional advice have contacted him after seeing the video and continue to do so. 
The survey carried out proved that practical workshops that actively involve participants in every stage of the process can result in improved maintenance of buildings. It is not known what are the actual effects of the more commonly organized "taster sessions", i.e. practical yet shorter events that provide only a brief introduction or skip certain stages of the process.

\subsection{Databases of contractors}

A common issue around Europe is the lack of qualified contractors that are capable and willing to take up repair works. Many heritage owners and managers encounter difficulties when looking for a good specialist. At the same time, some contractors that are new to the market find it hard to promote their services effectively and reach their target customers. In some European countries specialized databases exist that address these issues.

In addition to the registers of qualified specialists that are more common (e.g. Register of Craftsmen in Norway Håndverksregisteret), new types of databases started to appear that include additional services. For example, MaintenanceBooker.org.uk (launched in 2017 by the National Churches Trust) features a competitive tendering system. When the user of the site submits a quote request, various local and national contractors are invited to bid for the job. All the bidders are companies contracted for 4 years through an open tender process in which experience, qualifications and references were taken into consideration.

The Counselling Network for Rural Architecture was created in 2015 to facilitate owners of traditional buildings in rural areas of Estonia in getting professional advice. Its website

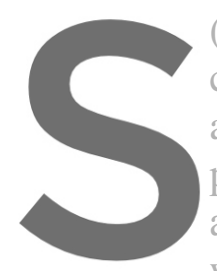
(www.maamaja.eu/) classified according area in which they op provide a defined cou assessment of the works, appropriate materials,
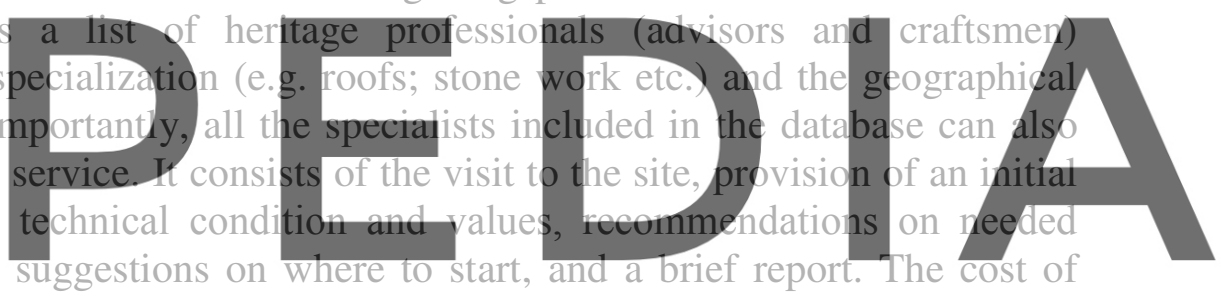
such subsidized consultation for the owner is set to only 30 euros + VAT + travel expenses,

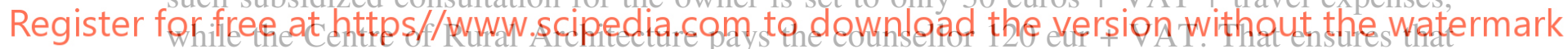

the model is viable - financially acceptable to both the owner and the specialist. Most of the

Centre's income is the support from the Ministry of Culture, the rest is generated from the organization of trainings and seminars, grants received from different foundations [12].

Such databases have not been found in places where MW services are present. However, members of MW schemes often ask to name specific contractors that could carry out the works indicated in the inspection report. They get disappointed as most of the MW organisations feel that the act of providing such recommendations would compromise their impartiality and reputation. Therefore, the existence of both models would ideally complement each other.

\subsection{Conservation manuals}

A lot of the information regarding built heritage and conservation is delivered in a very technical language which can discourage wider public to take interest in the subject. However, an increase in publications designed for those without academic and professional background in heritage has been observed in recent years. Among the examples seen, subjects covered include the maintenance of different parts of the building, the use of traditional materials, different types of structures, energy efficiency, guidance on legislative framework. 
Their preparation and/or distribution is often one of the functions of Monumentenwacht type of organisations and heritage centres. For example, the Engine Shed - building conservation centre in Stirling (run by Historic Environment Scotland) - has an excellent collection of short booklets and some longer publications covering almost every possible topic. Visitors of the centre are welcome to take them free of charge. They are also accessible online on the centre's website. Since the opening of the centre in 2017, a huge number of 34,5 thousand guides has been disseminated (not including e-versions downloaded) [13].

There are also quite interactive online versions such as "Under one roof" launched in Scotland (www.underoneroof.scot) for owners of common properties and their advisers. The website provides practical information and advice on repairs, helps to understand rights, responsibilities and steps to be taken.

Written conservation guidance could be considered as the most passive of the educational informational methods of encouraging heritage maintenance. Nonetheless, high numbers of copies being distributed show that they are of great interest to the public.

\section{COMBINATION OF SUPPORT AND ENFORCEMENT}

\section{All the previously mentioned practices try to improve the condition of built environment} by raising awareness, informing and educating. However, high percentages of historic buildings in poor condition suggest that such non-obligatory schemes may not be sufficient.

The Scottish House Condition Survey, carried out in 2016, found that almost half (48\%) of

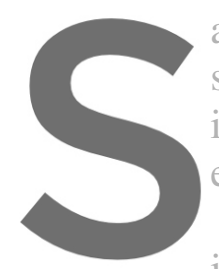
all dwellings and $67 \%$

stock) have disrepair to incidents of falling mas

evident that similar situr

Obligatory mainten

inspection of vehicles. It is
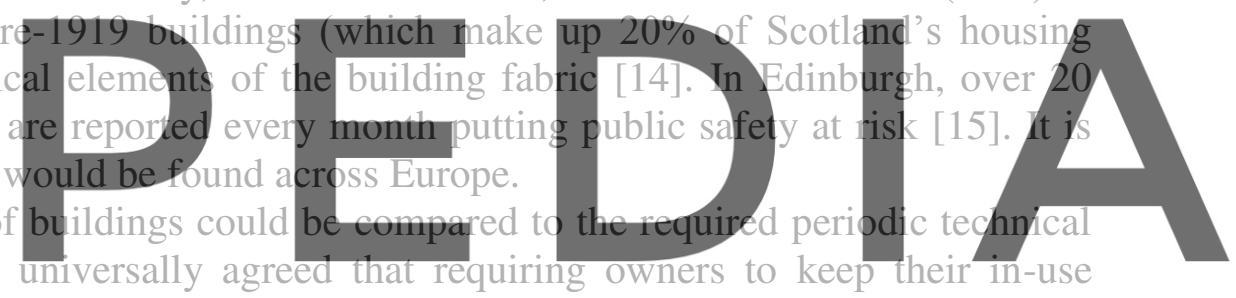

vehicles in good order has apparent benefits to the environment and the public safety. There

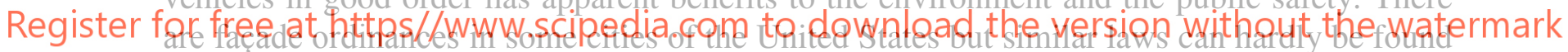

in Europe. Therefore, ongoing discussions and plans to introduce tenement maintenance legisiation in Scotiand are of great interest in this context.

Three main interlinked proposals put forward by the Scottish Parliamentary Working Group on Tenement Maintenance (established on March 2018) are: 1) Compulsory (not optional) Owners Associations (OA) and their status enhancement to legal entities; 2) Mandatory quinquennial property inspections; 3) Creation of Building Reserve Funds (BRF).

Regular inspections and reports would inform the planning of necessary repairs and expenditure. Reports would be made accessible to existing and prospective owners, as well as tenants, neighbours and policymakers. They would include inspection conclusions, prescribed works under different categories of urgency, indicative costings and information on any grants available. BRF would ensure better control, governance and transparency than OA held funds. It would feature a possibility to invest funds and make loans to owners whose funds are insufficient; ensure long term maintenance through funds being heritable (transmittable to future owners). BRFs would be held in a specially established, national or regional level fund (a form of social investment fund).

Full monitoring of how these laws are being followed could hardly be ensured. However, there are certain control mechanisms foreseen. For example, it would not be possible to sell a tenement flat or to get a grant without an inspection report. Also, if inspection reports were to be connected with Home Reports, the level of maintenance would be visible to potential 
tenants. Such situations would naturally force the owner to invest in maintenance and repairs even if not on the intervals required by law.

It is expected that it will take around ten years for this system to be fully launched due to the complexity of legislation to be introduced, the time needed to expand the pool of qualified people for inspections, to ensure the functionality of tools to be used, and to raise public awareness. From the viewpoint of Jocelyn Cunliffe (member of the Tenement Action Group), the assurance of grants' availability is key to the success of the scheme. It would motivate the owners and increase the demand for repairs, which, in turn, would ensure the vitality of the market. Ideally, fiscal incentives (such as the possibility to reclaim VAT for repairs) would also be in place [16].

\section{REMARKS ON THE COMMUNICATION OF MAINTENANCE IMPORTANCE}

All the discussed schemes are essentially driven by the same motives and the understanding of far-reaching benefits of regular maintenance. However, a review of communication messages in the websites of aforementioned organisations showed that an incomplete picture of preventive conservation impact is presented. Usually, communication evolves around the preservation of buildings' cultural or historical values. Other significant values and benefits (e.g. environmental) are rarely mentioned.

The global focus on climate change brought the attention to the fact that buildings and construction industry are the major drivers of energy demand and $\mathrm{CO} 2$ emissions. According to the 2018 data from the United Nations Environment Programme, the manufacture of building materials makes up $11 \%$ of total global greenhouse gas emissions [17]. In the heritage sector, these concerns seem to mainly manifest in increased efforts to 1) improve the energy efficiency of existing buildings through the means of insulation, and to 2) apply adaptive reuse on derelict or underused buildings. However, the potential to prolong the lives of buildings that are still in use through preventive conservation methods is not yet fully acknowledged. Aspects of embodied energy, long life-span of many original materials, the carbon footprint of construction could all be used as arguments in favour of regular buildings maintenance.

Apart from the positive impact on the environment, maintenance should also be discussed in connection to public safety, the rising value of historic properties, and the negative impact of many modern materials on human health. Researching and presenting a wider range of preventive conservation benefits would likely make the topic more engaging and relevant to the public and authorities.

\section{CONCLUSIONS}

Maintenance of historic buildings is being promoted by different types of organisations that apply distinct methods. Monumentenwacht type of organisations provide professional inspection services resulting in site specific recommendations. Necessary repairs that they indicate in condition reports require appropriate specialists. Some of the recently launched databases not only list qualified contractors but offer additional features (such as competitive tendering system) that effectively connect specialists with heritage owners. Some of the works can be carried out by the owners themselves but still require some knowledge and skill. They can be sought from heritage centres, conservation manuals and various events for the public. Practical workshops on wooden windows' maintenance were found to not only increase the appreciation of historic buildings but to actually result in improved heritage maintenance as a 
large proportion of participants apply the skills in practice. In Scotland, the foreseen legislation is expected to improve generally complicated maintenance of shared properties by enforcing quinquennial inspections among other requirements.

Therefore, all the different methods should be seen as integral parts of preventive conservation system rather than alternative methods. Also, all the models require substantial financial support to be feasible. In order to attract public and private investments, benefits of preventive conservation should be explored and presented beyond the preservation of historic or cultural value.

\section{REFERENCES}

[1] Proceedings of the First International Conference Monumentenwacht in Amsterdam, Netherlands held in 2000 (2002).

[2] Monumentenwacht Netherlands. https://www.monumenten.nl Accessed July 2019.

[3] Correspondence with Viltė Janušauskaitė (Head of Projects Department at the stateowned enterprise Lietuvos paminklai; project FIXUS). July-August 2019.

[4] Vandesande, Aziliz. Preventive Conservation Strategy for Built Heritage Aimed at Sustainable Management and Local Development (2017), 81.

[5] Goeleven, Carolien. "Monumentenwacht" (2016). http://www.changes-project.eu/wpcontent/uploads/2016/01/2016_05_26_Monza_Goedleven.pdf Accessed 30 July 2019.

[6] Proceedings of the conference "Introducing and Running Preventive Maintenance Services for Cultural Heritage Buildings", Budapest, 2014.

[7] Dann, Nigel. "Planned and Preventative Conservation \& England: Experiences, Opportunities and Requirements". Preventive and planned conservation conference, Monza, Montova, 2014.

[8] Correspondence with Sonya Linskaill (manager of the TBHC) in July-August 2019, and in person interview in Edinburgh on 8 August 2019.

[9] Monumentenwacht Noord-Brabant. "Noord-Brabant Meerjarenbeleidsplan 2019-2021". https://mwnb.nl/2019/03/08/meerjarenbeleidsplan-2019-2021/ Accessed 19 July 2019.

[10] Correspondence with Viltė Janušauskaitė (manager of FIXUS) and Branislav Reznik (manager of ProMonumenta). July -August 2019.

[11] EEA Grants Lithuania. Medinių langų ir durų restauravimas. https://www.youtube.com/watch?v=UBiTWFtu58g. Accessed on 30 April 2020.

[12] Correspondense with Elo Lutsepp (Head of the Centre of Rural Architecture, Estonian Open Air Museum). August 13, 2019.

[13] Correspondence with Dorothy Hoskins, Technical Outreach and Education Manager with Historic Environment Scotland (HES). July 26, 2019.

[14] Scottish Government. "Scottish house condition survey 2016: key findings". https://www.gov.scot/publications/scottish-house-condition-survey-2016-keyfindings/pages/8/ Accessed 5 July 2019.

[15] BBC News. "Very little done since Edinburgh falling masonry death". www.bbc.com/news/uk-scotland-edinburgh-east-fife-48526542 Accessed 25 July 2019.

[16] In-person interview with Jocelyn Cunliffe (architect, member of the Tenement Action Group) in Edinburgh on 30 July 2019.

[17] The European Commission. „Global Status Report 2017”. https://ec.europa.eu/energy/sites/ener/files/documents/020_fatih_birol_seif_paris_11-1217.pdf Accessed 20 July 2019. 